\title{
Knowledge, Attitude and Practice of Cervical Cancer Screening through Visual Inspection with Acetic Acid
}

\author{
Susmita Kar, Md. Kapil Ahmed \\ Department of Public Health, Daffodil International University, Bangladesh
}

\begin{tabular}{l}
\hline Article Info \\
\hline Article history: \\
Received Jun 6, 2017 \\
Revised Aug 8, 2017 \\
Accepted Aug 22, 2017 \\
\hline
\end{tabular}

\section{Keyword:}

Acetic acid

Adult women

Cervical cancer

Screening

Visual inspection

\begin{abstract}
Detection of the cervical cancer requires practice of screening that will increase survival rates from the disease. Visual Inspection with Acetic Acid (VIA) is an alternative to screening for cervical cancer.This study aims to assess the knowledge, attitude, and practice towards VIA screening among adult women. We used a cross-sectional study in urban areas of Bangladesh with a sample of 285 respondents those were interviewed through semistructured questionnaire. Analyses have done by targeting the objectives and considering the indicators with appropriate test statsitsics.About $56.1 \%$ respondents aged between 18 and 35 years with majority had at least secondary education including $29.5 \%$ were from affluent group. Though the highest majority of women had the knowledge of cervical cancer but only quarter was aware of VIA. A few of the respondents adopted any screening test for detecting cervical cancer and this lower coverage could be due to, among other reasons, lack of knowledge, accessibility, and service availability. The results also indicated that higher educational level of respondents is the predictor of improving knowledge on the disease and early adoption of available test procedure.An awareness building program should be designed for women of early detection of cervical cancer using VIA procedure.
\end{abstract}

Copyright $@ 2017$ Institute of Advanced Engineering and Science. All rights reserved.

\section{Corresponding Author:}

Susmita Kar,

Department of Public Health,

Daffodil International University,

4/2, Sobhanbag, Dhanmondi, Dhaka, Bangladesh.

Email: susmitak20@gmail.com

\section{INTRODUCTION}

Cervical cancer is the third commonest cancer among women worldwide [1],[2]. In 2012, statistics showed that 528,000 new cases and over 266000 deaths occurred due to the disease [3]. The low- and middle income countries suffer almost $90 \%$ of cervical cancer burden [4]. In Bangladesh, cervical cancer is the second most common cause of cancer deaths in women [1]. Annually, over 50 million women are at risk for cervical cancer, with 17,686 cases diagnosed and 10,362 deaths each year in Bangladesh [5]. It is projected that by 2025, these numbers will increase to over 31,000 new cases each year and over 18,000 deaths [6]. These deaths often occur in relatively young women, who are raising children, caring for their families, and contributing to the communities.

Reported mortality rates in developed countries with successful screening programmes seldom exceed 5 per 100,000 women [7]. Cervical screening can possibly incredibly lessen deaths from cervical cancer; it is vital challenge for developing countries to strengthen the scope of cervical screening. One of the most important methods of prevention of cervical cancer is early detection, which includes routine cervical screening that can lead to diagnosis and treatment of cervical lesions before their progression to cervical cancer [8],[9]. By doing early treatment and cervical cancer screening, numerous countries have lessen their morbidity and mortality [10]. Bangladesh government including various development partners and NGO's 
(non government organization) has taken programmatic steps towards controlling cervical cancer. By developing cervical cancer screening program Visual Inspection with Acetic Acid (VIA) have already been recommended for women.

In spite of economic support, conservative society unable to provide proper health awareness to the women of Bangladesh that causes massive threat for the whole society. Regarding successful prevention of invasive cervical cancer Bangladesh still facing some challenges like infrastructure constrains, its importance, patient noncompliance, etc. On the other hand, low screening coverage could be due to lack of knowledge on cervical cancer and screening, especially in Urban setting where VIA screening is available. Knowledge regarding cervical cancer is essential for identifying this diseases; thus women should cautious, motivate and having positive approach to practice of screening for cervical cancer. Not much is known about Bangladeshi women knowledge, attitude and practice towards cervical carcinoma screening.

Bangladesh Government has taken programmatic steps towards controlling cervical cancer by developing cervical cancer screening program [11]. Also various development partners and NGO's are working in this field. There is media campaign for awareness development. Screening methods including VIA have already been recommended for women. Accurate information and knowledge about cervical cancer screening importantly influence women's cervical screening participation. Cervical screening, particularly VIA attendance is likely to be affected by knowledge, health perception of women. For the screening methods to be fully utilized, women need to be aware of the availability of the methods and to have knowledge of the screening methods. Detection of the cervical cancer requires knowledge on the disease so that women are aware, as well as motivation and hence have positive attitude towards practice of screening for cervical cancer. Not much is known about Bangladeshi women knowledge, attitude and practice towards cervical carcinoma screening. Even few academic researches on cervical cancer screening exist in Bangladesh, which needs to undertake this research on the above title of the research mentioned issue. This study aimed to looking on how knowledge able on this screening was, what was therefore their attitude and practice on screening for cervical cancer. Information obtained from this study should alert authorities and service providers so that proper measures can be taken to save the lives of Bangladeshi women by educating them on the importance of the screening services available in many places.

This study aims to assess the level of knowledge, attitude and practice on cervical cancer screening through VIA among women in urban area of Bangladesh.

\section{METHOD}

\subsection{Study area}

The study was incorporated the sample population in representative way and the entire population of different school premises where women were gathered, garments factories, slum areas, some residence areas, university campus, organization's offices and corporate office premises. The research participants were the adult residents of Dhaka urban area which were recruited purposively on the basis of inclusion and exclusion criteria. In inclusion criteria respondents must be female residing at Dhaka urban area and their age must be 18 years and above, eventually their participation should be voluntary. Co-morbid mental problems and residents who were travelling of the city must be excluded. The entire study duration was between November 2015 and July 2016. However the data collection period was November 2015 to January 2016.

\subsection{Sample size determination}

A representative sample size was determined by using the standard statistical formula: $\mathrm{n}=\mathrm{z} 2 \mathrm{pq} / \mathrm{d} 2$, Where $n=$ sample size, $\mathrm{z}=1.96$ (95\% confidence interval), $\mathrm{p}=$ prevalence of women knowledge, attitude and perception towards VIA screening, which is unknown (50\%, i.e. 0.50$), \mathrm{q}=1-\mathrm{p}$ and $\mathrm{d}=\mathrm{margin}$ of error $6 \%$, i.e. 0.06. That produced an approximate sample size 267. Excepting some non-response during data collection, considered $10 \%$ additional sample as non responses, which has given the sample size 294 , so the required total sample for this study should be approximately 295. It is mentionable that after completion of data collection, questionnaire checking has initially been done for ensuring completeness, as well as for quality information. In this process, a total of 10 question-answers of respondents were excluded and finally the study included 285 samples for analysis.

\subsection{Sampling technique}

As the VIA screening is available in many public and private health service facilities in Dhaka city, the respondents were selected from different women gathering of Dhaka city areas. The variation of the respondents in different areas was dependent on the gathering and accessibility of respondents during data collection of the respective study areas. 


\subsection{Development of Research instrument}

In this study data was collected by using semi-structured questionnaire. A questionnaire was developed after rigorous review of the available research documents and was pretested for gathering feedback on the suitability and appropriateness of the question. Before finalization of the questionnaire, English version was translated into Bengali. Informed of written consent was taken from the participants and ethical clearance obtained from the Department of Public Health under the faculty of Allied Health Sciences, Daffodil International University, Bangladesh.

\subsection{Statistical analysis}

The collected data were then edited, coded and entered into the computer through a designed data capturing format in SPSS software. Analyses have done by targeting the study objectives and by considering the indicators. Descriptive analyses of all relevant variables were done by using Measures of Central Tendency, Depression, Confidence Interval, etc. Association and differentiation within/between variables were tested by using appropriate test statistics.

\section{RESULTS}

\subsection{Socio demographic characteristics}

Socio demographic factors were arranged in the Table 1 according to participants' marital status, age, education, occupation, monthly family income and number of children.

Table 1. Socioeconomic Status of the Respondents $(\mathrm{n}=285)$

\begin{tabular}{|c|c|c|}
\hline & Frequency & $\%$ \\
\hline \multicolumn{3}{|l|}{ Marital Status } \\
\hline Unmarried & 35 & 12.3 \\
\hline Married & 243 & 85.3 \\
\hline Divorced & 3 & 1.1 \\
\hline Others & 4 & 1.4 \\
\hline \multicolumn{3}{|l|}{ Age } \\
\hline $18-23$ & 30 & 10.5 \\
\hline $24-29$ & 59 & 20.7 \\
\hline $30-35$ & 73 & 25.6 \\
\hline $36-41$ & 44 & 15.4 \\
\hline $42-47$ & 42 & 14.7 \\
\hline $48-53$ & 21 & 7.4 \\
\hline $54 \&$ Above & 16 & 5.6 \\
\hline \multicolumn{3}{|l|}{ Education } \\
\hline Illiterate & 41 & 14.4 \\
\hline Primary & 43 & 15.1 \\
\hline Under graduate & 93 & 32.6 \\
\hline Graduate and above & 100 & 5.1 \\
\hline Others & 8 & 2.8 \\
\hline \multicolumn{3}{|l|}{ Occupation } \\
\hline Service & 144 & 50.5 \\
\hline Business & 6 & 2.1 \\
\hline Unemployed & 11 & 3.9 \\
\hline Housewife & 124 & 43.5 \\
\hline \multicolumn{3}{|c|}{ Monthly Family Income (in thousands) Tk. } \\
\hline $0-10$ & 75 & 26.3 \\
\hline $11-20$ & 47 & 16.5 \\
\hline $21-30$ & 23 & 8.1 \\
\hline $31-40$ & 21 & 7.4 \\
\hline $41-50$ & 35 & 12.3 \\
\hline $51 \&$ Above & 84 & 29.5 \\
\hline \multicolumn{3}{|l|}{ No. of Children } \\
\hline 0 & 63 & 22.1 \\
\hline 1 & 60 & 21.1 \\
\hline 2 & 101 & 35.4 \\
\hline 3 & 39 & 13.7 \\
\hline 4 & 15 & 5.3 \\
\hline 5 & 3 & 1.1 \\
\hline 6 & 4 & 1.4 \\
\hline
\end{tabular}

The results showed that most of the respondents $(85.3 \%)$ were married. The major portions of the respondents were in reproductive age. The results indicated that more than half of the women $(56.8 \%)$ who 
participated in the in the study were either young or young adults (aged 18-35 years).Regarding respondents education it is indicated that majority of the respondents $(67.7 \%)$ were highly educated in our country context, even a lower proportion of illiterate women participated in this study.

\subsection{Knowledge and practice towards screening of VIA for cervical cancer}

Figure 1 documented that majority of study respondents have had the knowledge about the cervical cancer but only a little higher than one-quarter of the respondents heard about VIA test for cervical cancer.

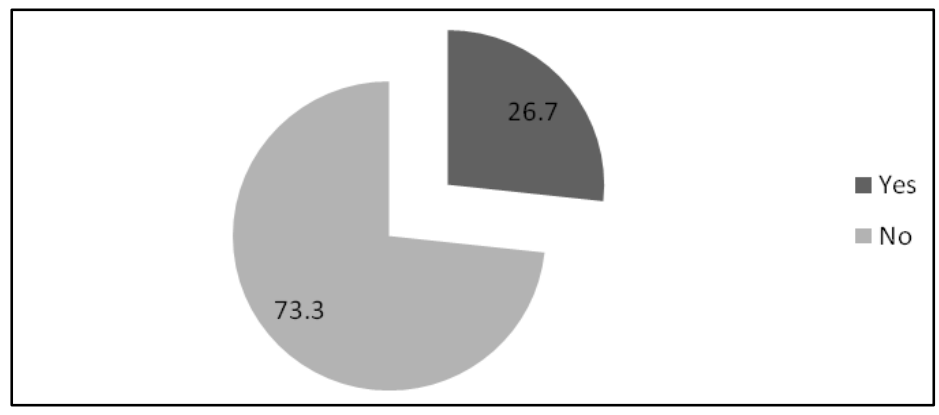

Figure 1. Ever heard about VIA test for cervical cancer $(\%, \mathrm{n}=285)$

Figure 2 shows that only $8.1 \%(n=6)$ of respondents who heard about the VIA test had practiced the same procedure for detecting the cervical cancer while a large proportion of respondents $(91.9 \%)$ those knew about the procedure but not yet tested through VIA.

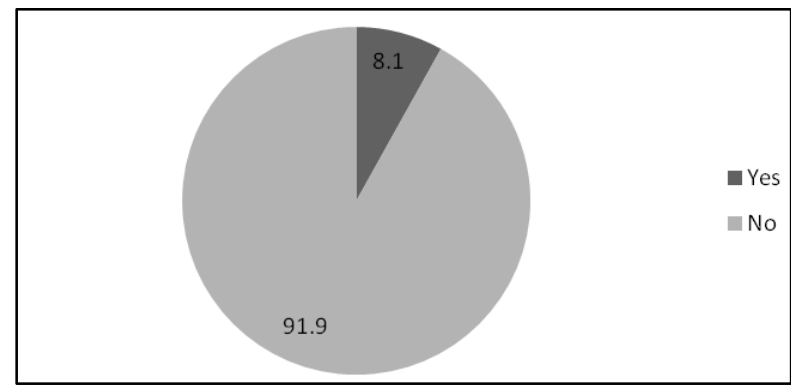

Figure 2. Ever been tested VIA for cervical cancer $(\%, n=79)$

Even respondents of this study were asked about the adoption of any other screening or testing for cervical cancer and a lower proportion $(21.1 \%)$ of them have the positive answer compared to a large proportion $(78.9 \%)$ of their counterparts as shown in Figure 3.

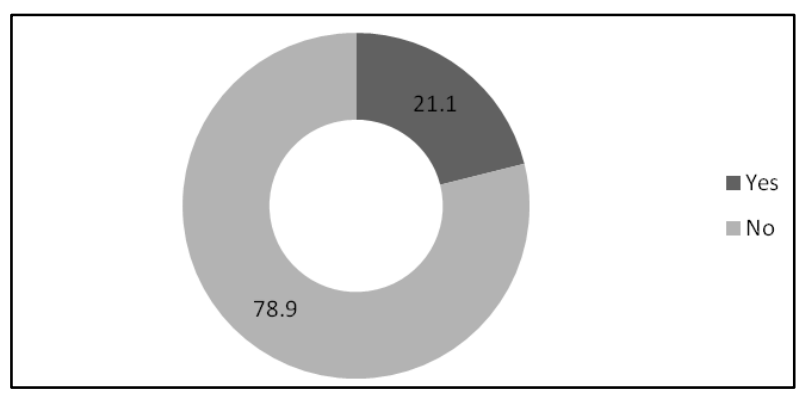

Figure 3. Ever been screened or adopted any other tested for cervical cancer $(\%, n=285)$ 
Figure 4 shows that about three quarter $(75.8 \%)$ of respondent did not have knowledge about the purpose of VIA test; on the contrary, only about a quarter $(24.2 \%)$ of respondent knew the reason to do VIA test.

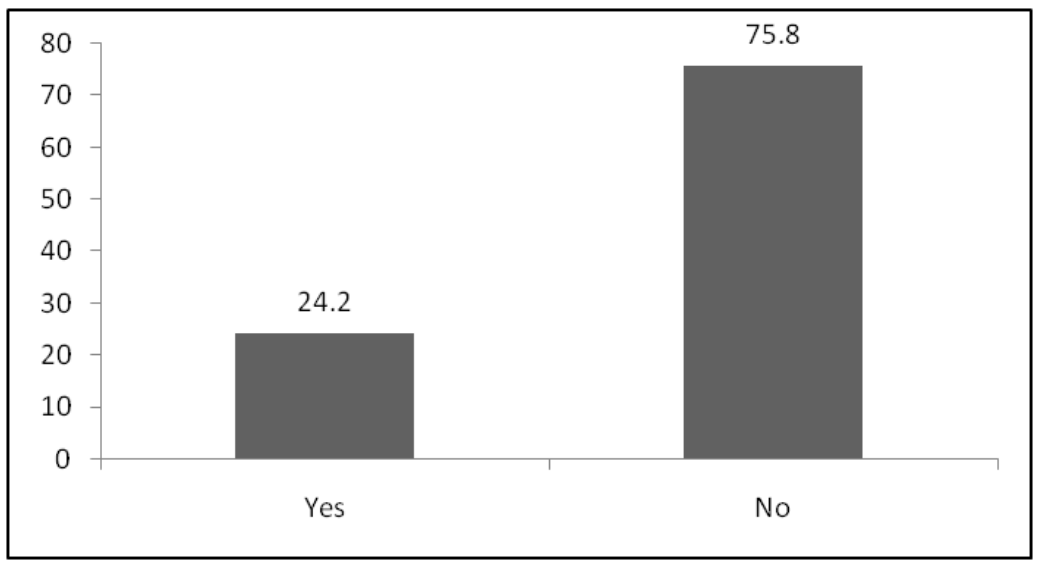

Figure 4. Knowledge on the purpose of VIA test $(\%, n=285)$

Even more than three quarter $(77.2 \%)$ of the respondent did not know where the VIA screening take place; however, less than a quarter $(22.8 \%)$ of respondent had the information of the place of VIA test as shown in Figure 5.

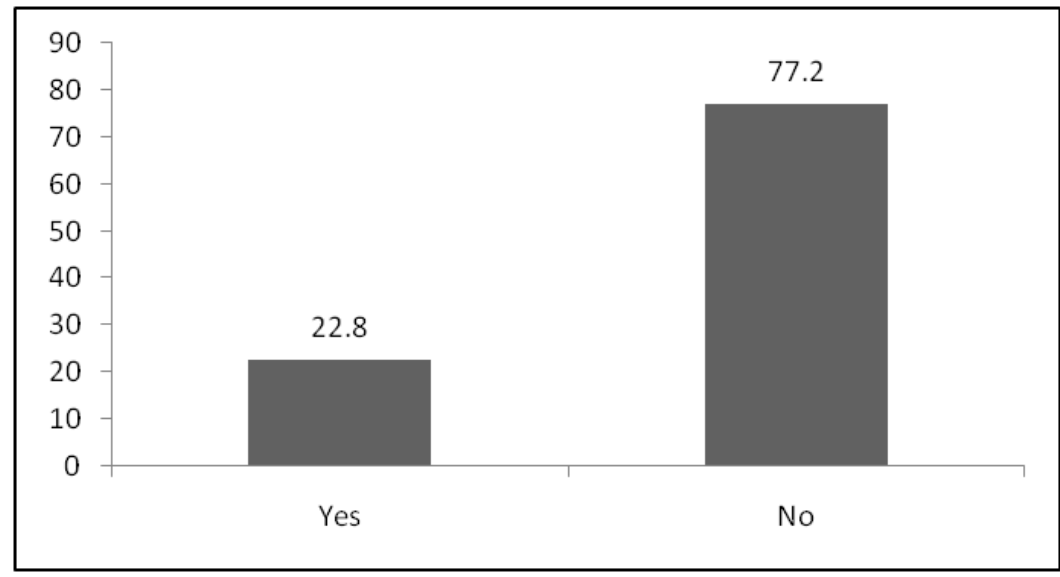

Figure 5. Familiarity with the place of VIA test $(\%, n=285)$

\subsection{Knowledge and attitude towards screening of VIA for cervical cancer}

Respondents' knowledge and attitude towards VIA test was summarized Table 2. The table shows that $72.3 \%$ respondent did not know that VIA test can indentify cervical cancer; at the same time, about three quarter of the respondents did not know that free of cost VIA test is available in government and urban hospitals. Moreover, $71.9 \%$ respondent had no idea that through the screening of VIA cervical cancer can protect. 
Table 2. Knowledge and Attitude of VIA Test $(n=285)$

\begin{tabular}{|c|c|c|}
\hline & Frequency & $\%$ \\
\hline \multicolumn{3}{|c|}{ VIA test can identify cervical cancer } \\
\hline Strongly disagree & 2 & 0.7 \\
\hline Disagree & 1 & 0.4 \\
\hline Neutral & 6 & 2.1 \\
\hline Agree & 52 & 18.2 \\
\hline Strongly agree & 18 & 6.3 \\
\hline Don't know & 206 & 72.3 \\
\hline \multicolumn{3}{|c|}{ Knowledge on free of cost of VIA test available in government and urban hospital } \\
\hline Strongly disagree & 3 & 1.1 \\
\hline Disagree & 5 & 1.8 \\
\hline Neutral & 12 & 4.2 \\
\hline Agree & 40 & 14 \\
\hline Strongly agree & 10 & 3.5 \\
\hline Don't know & 215 & 75.4 \\
\hline \multicolumn{3}{|c|}{ VIA Test should be done only by female healthworker } \\
\hline Strongly disagree & 1 & 0.4 \\
\hline Disagree & 2 & 0.7 \\
\hline Neutral & 13 & 4.6 \\
\hline Agree & 35 & 12.3 \\
\hline Strongly agree & 24 & 8.4 \\
\hline Don't know & 210 & 73.7 \\
\hline \multicolumn{3}{|c|}{ Health workers performance is worthy in creating awareness of VIA test } \\
\hline Strongly disagree & 3 & 1.1 \\
\hline Disagree & 6 & 2.1 \\
\hline Neutral & 8 & 2.8 \\
\hline Agree & 48 & 16.8 \\
\hline Strongly agree & 19 & 6.7 \\
\hline Don't know & 201 & 70.5 \\
\hline \multicolumn{3}{|c|}{ Women with menopause are not required of VIA test } \\
\hline Strongly disagree & 18 & 6.3 \\
\hline Disagree & 22 & 7.7 \\
\hline Neutral & 10 & 3.5 \\
\hline Agree & 15 & 5.3 \\
\hline Strongly agree & 5 & 1.8 \\
\hline Don't know & 215 & 75.4 \\
\hline \multicolumn{3}{|c|}{ VIA Test is not important for healthy woman } \\
\hline Strongly disagree & 24 & 8.4 \\
\hline Disagree & 34 & 11.9 \\
\hline Neutral & 10 & 3.5 \\
\hline Agree & 10 & 3.5 \\
\hline Strongly agree & 3 & 1.1 \\
\hline Don't know & 204 & 71.6 \\
\hline \multicolumn{3}{|c|}{ VIA test is needed only those who have family history } \\
\hline Strongly disagree & 6 & 2.1 \\
\hline Disagree & 8 & 2.8 \\
\hline Neutral & 5 & 1.8 \\
\hline Agree & 45 & 15.8 \\
\hline Strongly agree & 24 & 8.4 \\
\hline Don't know & 197 & 69.1 \\
\hline \multicolumn{3}{|c|}{ Cervical cancer can be protected through VIA test } \\
\hline Strongly disagree & 2 & 0.7 \\
\hline Disagree & 6 & 2.1 \\
\hline Neutral & 5 & 1.8 \\
\hline Agree & 53 & 18.6 \\
\hline Strongly agree & 14 & 4.9 \\
\hline Don't know & 205 & 71.9 \\
\hline
\end{tabular}

*Scaling questionnaire were presented to the participants for knowledge and attitude of VIA test

\subsection{Factor associated with cervical cancer screening through VIA test}

Some bi-variate analyses was done with the respondent's knowledge on cervical cancer for VIA test and availability of services according to women' marital status, number of children, education and economic condition. Appropriate statistical test was done to see the association and differentiation of independent with dependent variables. Respondent's knowledge on VIA test for cervical cancer was varied by their marital status that showed in Table 3. 
Table 3. Factors Associated with Cervical Cancer Screening through VIA Test $(\mathrm{n}=285)$

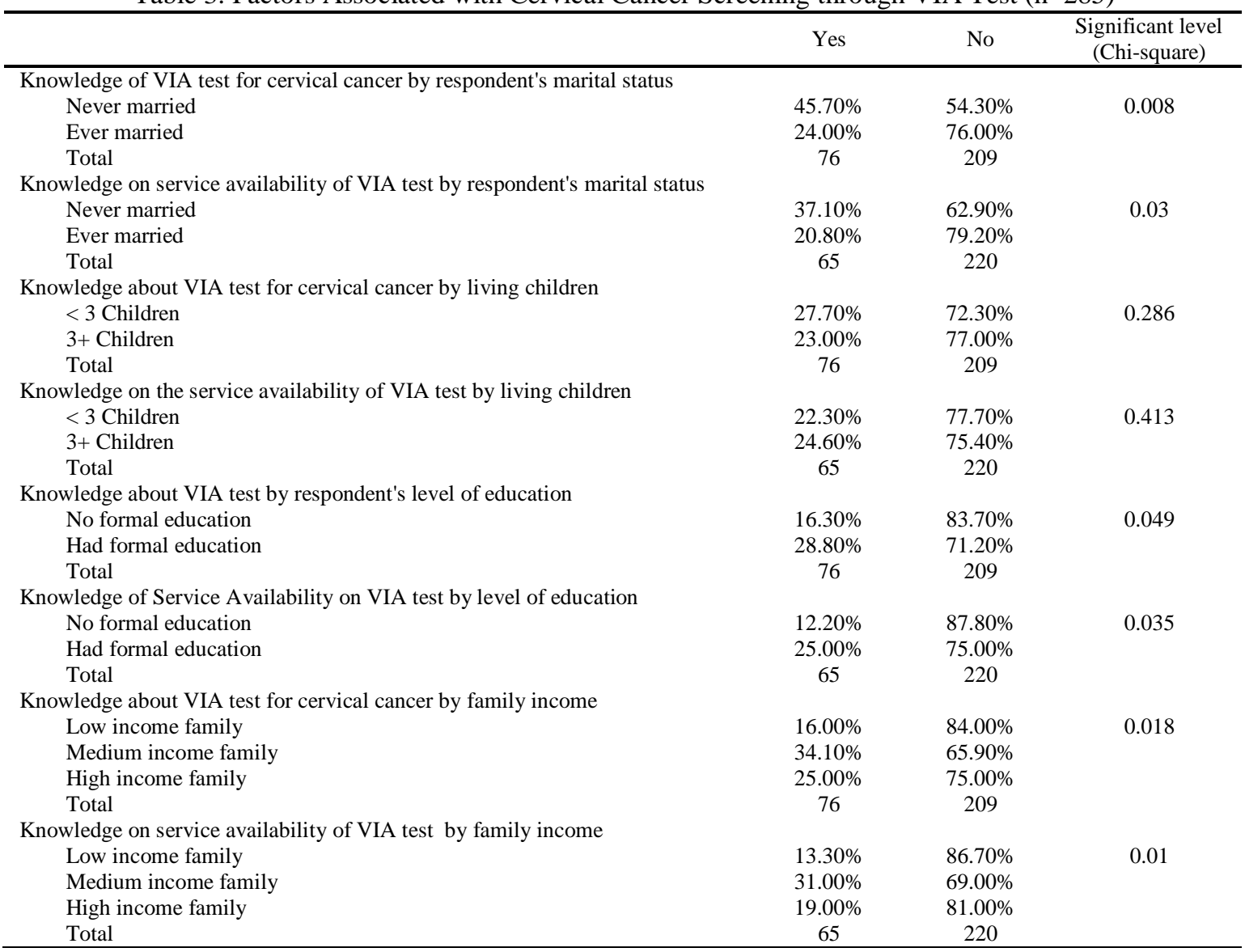

Table 3 shows that the never married respondents have the knowledge on cervical a significant differences $(\mathrm{p}<0.01)$ was found to the respondent's knowledge on VIA test for cervical cancer with their marital status where a higher proportion $(45.7 \%)$ of never married have the knowledge on VIA test compared to their counterpart ever married women $(24.0 \%)$. Again, the prevailing better knowledge of VIA test among never married women is probably because of more exposure to the procedure through better publicity in recent time on the examination of women cervical cancer. Once more, a significant differences $(\mathrm{p}<0.05)$ was found to the respondent knowledge on the availability of VIA test for cervical cancer with their marital status where a higher proportion $(37.1 \%)$ of never married have the knowledge on the availability of VIA test compared to their counterpart ever married women $(20.8 \%)$. The prevailing better knowledge on the availability of VIA test among never married women was due to the reasons of comparative better sources of knowledge as of married women. On the other hand, respondent's knowledge on service availability on VIA test was significantly $(\mathrm{p}<0.05)$ differences between women level of education. Respondents who had no formal education were less knowledgeable (12.2\%) than women who had some formal education $(25.0 \%)$. Again, Respondent's knowledge on VIA test for cervical cancer according to their family income level showed a significant differences $(\mathrm{p}<0.05)$ between low income family and medium income or high income family. Respondent's knowledge on service availability of VIA test for cervical cancer according to respondent's family income showed in same table. Respondents from low income family had less knowledge $(13.3 \%)$ on the service availability of VIA test than their counterparts medium $(31.0 \%)$ and high income $(19.0 \%)$ respondents, which difference is statistically significant $(\mathrm{p}<0.05)$.

\section{DISCUSSION}

Detection of the cervical cancer requires knowledge on the disease so that women are aware, as well as motivation and hence have positive attitude towards practice of screening for this. Though screening methods including VIA have already been recommended for women and number of studies documented that the VIA procedure has been set up as a successful other option to cytology based screening with its high 
sensitivity, economical if patients have knowledge about the diseaseand low level of health care [12]. Moreover, the level of consciousness and early approach of patients towards procedure increased the chance of disease by detecting for treatment [13]. A study conducted in Ghana revealed that accurate information and knowledge about the screening importantly influence women's cervical screening participation [14] and Bangladeshi women are not exceptional of this consensus. This descriptive study was gathered information on women's knowledge, attitude and practice of VIA screening. The study results showed that more than half of the respondents of this study were aged 18-35 years. A highest majority of respondents was married with at least some formal education and had the knowledge of cervical cancer including its primary protection. The study revealed that both print and electronic media enriched women's on the disease and way of prevention.

The results also showed that majority of the women felt encouragement to do the screening or make any test for detecting the cervical cancer if the procedure of screening is either less costly or completely free even having convenient location. The study result is comparable with the other study e.g. factors like specific information on how to prevent the disease as well as service availability of its screening; even cervical cancer screening services within short distances of women dwelling place are significantly influencing woman participation to cervical cancer screening [15]. Again, due to lack of motivations and unknowingness influence women's to receive any screening to detect the disease [16] which is also importance of the detection of cervical cancer by adopting any procedures available in the any service provisions. A study in South Africa showed that in spite of having knowledge and availability of services about $87 \%$ of women from higher society and educational backgrounds did not go through for cervical screening [17], [18]. The study results also revealed that only one-quarter of the respondents heard about the screening test VIA that detect cervical cancer and can be taken necessary measure beforehand. Moreover, a higher proportion of respondents still believed some the misconceptions like test not done by female providers, healthy and menopause women need not to adopt any screening procedure; family history of this disease is not a matter, etc. All these were assertive factors that women are not adopting any screening or test procedure to protect cervical cancer. The inferential analysis of the study documented that respondent's knowledge on VIA screening method was significantly varied by their marital status. Never married respondents have the higher proportion of knowledge on VIA test and available sources compared to their counterpart ever married women.Some studies have found that single women are more likely than married women to have pap screening [19]. Again educational level of respondents was significantly associated with some of dependent variables, e.g. respondents who had no formal education were less knowledgeable about screening procedures and service amiability than the respondents who had at least some formal education. The prevailing knowledge on procedure and its availability was better among never married and educated women is probably because of more media exposure through better publicity in recent time on the examination of women cervical cancer. The study conducted in Nepal resealed that lack of education and confusing attitude towards gynecological symptoms is responsible for delay diagnosis of cervical cancer [20],[21]. The prevailing knowledge on procedure and its availability was better among never married and educated women is probably because of more media exposure through better publicity in recent time on the examination of women cervical cancer.

\section{CONCLUSION}

The study results indicated that majority of the study respondents were not adopting the screening procedure to avoid morbidity and mortality from cervical cancer due to misconception and fear. Awareness building program should be designed for this segment of women for protecting them from this diseases through early detection screening procedure like VIA test. Even, the implementation of behavior change communication program by the government would be familiarized the procedures of screening for cervical cancer among women. In prevailing cultural conservative society in Bangladesh, women who are porn to disease should more aware on the severity of cervical cancer Moreover, through diversified exposure like publicity over media that could increase woman's knowledge on the test procedure for protecting them from the same disease. Further in-depth study should be initiated conserving various aspects perceived barriers towards the screening cervical screening.

\section{ACKNOWLEDGEMENTS}

It is our profound privilege to express my sense of gratitude to all the members of the Faculty, Department of Public Health, Daffodil International University, Dhaka, for their sagacious guidance and expert views during the course of study and various inputs in the manuscript. We greatly acknowledge my friend, Dr. Sohela Mustari for her guidance and help for completing this venture. 


\section{REFERENCES}

[1] Ferlay J., et al., "Estimates of worldwide burden of cancer in 2008: GLOBOCAN 2008," International journal of cancer, vol/issue: 127(12), pp. 2893-2917, 2010.

[2] Jemal A., et al., "Global cancer statistics," CA: a cancer journal for clinicians, vol/issue: 61(2), pp. 69-90, 2011.

[3] Simayi D., et al., "Implementing a cervical cancer awareness program in low-income settings in Western China: a community-based locally affordable intervention for risk reduction," Asian Pacific Journal of Cancer Prevention, vol/issue: 14(12), pp. 7459-7466, 2013.

[4] WHO, "Comprehensive cervical cancer control: a guide to essential practice," World Health Organization, 2014.

[5] Bradford L. S., et al., "Development of a Cervical Cancer Screening Program in a Slum Setting Using Visual Inspection with Acetic Acid: Analysis of Feasibility and Cost," Open Journal of Obstetrics and Gynecology, vol/issue: 2(2), pp. 140-146, 2012.

[6] WHO, "WHO/ICO Information Centre on HPV and Cervical Cancer. Human Papillomavirus and Related Cancers in Kenya. Summary Report 2010," World Health Organization, 2010.

[7] John J., "The knowledge, attitude, practice and perceived barriers towards screening for premalignant cervical lesions among women aged 18years and above, in Songea urban, Ruvuma," A dissertation submitted to the Department of Health and Allied Sciences at Muhimbili University for the Degree of Master of Medicine (Obstetrics and Gynecology), Tanzania, 2011.

[8] Schiffman M., et al., "Human papillomavirus and cervical cancer," The Lancet, vol/issue: 370(9590), pp. 890-907, 2007.

[9] Schiffman M., et al., "Human papillomavirus testing in the prevention of cervical cancer," Journal of the National Cancer Institute, vol/issue: 103(5), pp. 368-383, 2011.

[10] Urasa M. and Darj E., "Knowledge of cervical cancer and screening practices of nurses at a regional hospital in Tanzania," African health sciences, vol/issue: 11(1), pp. 48-57, 2011.

[11] Rahman M. A., et al., "Gynaecological Cancers in Surgical Specimens-A Hospital Based Analysis," Medicine Today, vol/issue: 26(2), pp. 78-82, 2015.

[12] Shekhar S., et al., "Cervical cancer screening: knowledge, attitude and practices among nursing staff in a tertiary level teaching institution of rural India," Asian Pacific Journal of Cancer Prevention, vol/issue: 14(6), pp. 3641$3645,2013$.

[13] F. Getahun, et al., "Comprehensive knowledge about cervical cancer is low among women in Northwest Ethiopia," BMC cancer, vol/issue: 13(1), pp. 2, 2013.

[14] Abotchie P. N. and Shokar N. K., "Cervical cancer screening among college students in Ghana: knowledge and health beliefs," International journal of gynecological cancer: official journal of the International Gynecological Cancer Society., vol/issue: 19(3), pp. 412, 2009.

[15] Lyimo F. S. and Beran T. N., "Demographic, knowledge, attitudinal, and accessibility factors associated with uptake of cervical cancer screening among women in a rural district of Tanzania: three public policy implications," BMC public health, vol/issue: 12(1), pp. 22, 2012.

[16] Gu C., et al., "Chinese women's motivation to receive future screening: the role of social-demographic factors, knowledge and risk perception of cervical cancer," European Journal of Oncology Nursing, vol/issue: 17(2), pp. 154-161, 2013.

[17] Kei R. M., et al., "Challenges of Cervical Cancer Screening Among Women of Reproductive Age in Kisii Town, Kisii County, Kenya," Science Journal of Public Health, vol/issue: 4(4), pp. 289-966, 2016.

[18] Matangaidze O., "Knowledge, attitude and practices of HIV infected women on cervical cancer screening at Musiso Mission Hospital, Masvingo Province, Zimbabwe Research Project," A Doctoral dissertation submitted to University of Limpopo, Zimbabwe, 2015.

[19] Lyimo F. S. and Beran T. N., "Demographic, knowledge, attitudinal, and accessibility factors associated with uptake of cervical cancer screening among women in a rural district of Tanzania: three public policy implications," BMC public health, vol/issue: 12(1), pp. 22, 2012.

[20] Gyenwali D., et al., "Factors associated with late diagnosis of cervical cancer in Nepal," Asian Pacific Journal of Cancer Prevention, vol/issue: 14(7), pp. 4373-4377, 2013.

[21] Fort V. K., et al., "Barriers to cervical cancer screening in Mulanje, Malawi: a qualitative study," Patient preference and adherence, vol. 5, pp. 125, 2011.

\section{BIOGRAPHIES OF AUTHORS}

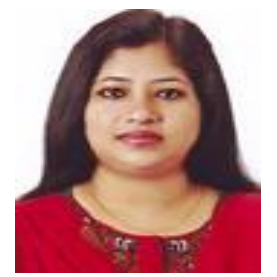

Name: Susmita Kar

Email: susmitak20@gmail.com. I have completed Master Degree in Public Health from the faculty of Allied Health Science of Daffodil International Universitylocated at 4/2, Sobhanbag, Dhanmondi, Dhaka, Bangladesh. 


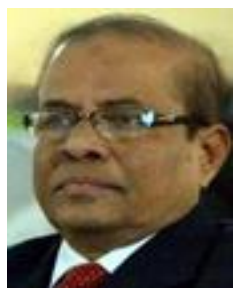

Name: Dr. Kapil Ahmed

Email: mdkapilahmed@gmail.com. I am currently working as Deputy Director (Research \& Evaluation), Bangladesh Center for Communication Programs (BCCP).I was the former faculty of the Department of Public Health of the faculty of Allied Health Science of Daffodil International University in Bangladesh. In addition, I worked as Epidemiologist/Demographer in the United Kingdom with Health Surveillance Systems along with other Public Health related Programs. Moreover, I started my professional career in early 1980s with an International Research Organization in Bangladesh where broadened the knowledge to expose into the public health professional and obtained basic training on statistics (B.Sc. \& M.Sc.), then another Master in Master in Population Study and PhD in Demography. 